\title{
Preparation of Reduced Graphene Oxide Aerogel and its Application in Lithium Sulfur Battery
}

\author{
Jianrong Xiao ${ }^{1, *}$, Zhiyun Yang ${ }^{1}$, Hongzhe Wang $^{2}$, Yafang Guo ${ }^{1}$, Zengren Tao ${ }^{1}$ \\ ${ }^{1}$ College of Science, Guilin University of Technology, Guilin 541004, Guangxi Province, China \\ ${ }^{2}$ School of Materials Science and Engineering, Science and Engineering, Southeast University, \\ Nanjing 211189, Jiangsu Province, China \\ *E-mail: xjr@glut.edu.cn
}

doi: $10.20964 / 2017.12 .450$

Received: 31 August 2017 / Accepted: 11 October 2017 / Published: 12 November 2017

\begin{abstract}
A facile method was used to prepare novel nitrogen-doped sulfur-based compound material coated with reduced-graphene-oxide aerogel NCNT/S(RGO-gel) composite. As coating layer, the material was systematically studied through X-ray diffraction, scanning electron microscopy, Fourier transform infrared spectroscopy, and electrochemical test. NCNT/S(RGO-gel) electrode showed first discharge specific capacity of $1403.7 \mathrm{mAh} \cdot \mathrm{g}^{-1}$ under $500 \mathrm{~mA} / \mathrm{g}$ density. The material also exhibited outstanding rate capability and long-term cycle stability. Results showed that RGO-gel coated composite electrode retained its discharge specific capacity of $912.4 \mathrm{mAh} / \mathrm{g}$ after 175 cycles under $500 \mathrm{~mA} / \mathrm{g}$ current density. The composite electrode presented capacity retention rate of $80 \%$. Improved electrochemical performance was mainly ascribed to RGO-gel, which not only reduced dissolution of sulfur polymer $\left(\mathrm{S}_{\mathrm{n}}{ }^{2-}\right)$ but also significantly improved conductivity. NCNT also served as bridge between RGO-gel layers, significantly shortening the path for lithium-ion transport. Thus, novel NCNT/S(RGO-gel) composite can act as potential positive electrode for high performance $\mathrm{Li}-\mathrm{S}$ batteries.
\end{abstract}

Keywords: RGO-gel, coating layer, Li-S battery, electrochemical performance

\section{FULL TEXT}

(C) 2017 The Authors. Published by ESG (www.electrochemsci.org). This article is an open access article distributed under the terms and conditions of the Creative Commons Attribution license (http://creativecommons.org/licenses/by/4.0/). 